\title{
Apresentação Pediátrica da Síndrome Antifosfolípide
}

\section{Paediatric Antiphospholipid Syndrome Presentation}

\author{
Juliana de Oliveira Sato ${ }^{(1)}$, Simone Manso de Carvalho ${ }^{(1)}$, Claudia Saad Magalhães ${ }^{(2)}$
}

\section{RESUMO}

Objetivo: Descrever as características clínicas, laboratoriais e de desfecho de uma série de casos com diagnóstico definido de síndrome antifosfolípide (SAF) pediátrica. Métodos: Estudo observacionalretrospectivo de referência pediátrica terciária, que identificou os casos por meio de evento vascular, trombose venosa ou oclusão arterial, determinação de anticorpos anticardiolipina ( $\operatorname{IgG}$ e $\operatorname{IgM}$ ) e teste do anticoagulante lúpico. Resultados: Foram identificados cinco casos atendidos nos últimos cinco anos, sendo dois meninos e três meninas. A trombose venosa ocorreu em seios venosos cerebrais (2), fibular (2), poplítea (1), femoral (1), intestinal (1), renal (1), acompanhados por oclusão arterial intestinal (1), de artéria renal (1) e artéria digital (1), esta resultando gangrena periférica como evento recorrente durante anticoagulação com warfarina. Um abortamento espontâneo ocorreu em uma adolescente em vigência de púrpura trombocitopênica, evoluindo com anemia hemolítica (síndrome de Evans) e desfecho fatal por hemorragia. A investigação laboratorial em todos os casos resultou, pelo menos, uma determinação positiva de anticardiolipina IgG e/ou IgM, sendo considerados como SAF primária. Três dos casos estão em seguimento com anticoagulação oral. Conclusão: A trombose venosa cerebral e de extremidades foram os eventos mais freqüentes. A presente série alerta para a investigação e o diagnóstico precoces, com abordagem multidisciplinar para o tratamento.

Palavras-chave: anticorpos anticardiolipina, síndrome antifosfolípide, síndrome de Evans, trombose.

\section{INTRODUÇÃO}

Anticorpo antifosfolípide (APA) é a designação genérica que descreve o grupo heterogêneo de auto-anticorpos contra fosfolípides de carga negativa ou proteína-ligantes plasmáticas. Há numerosos estudos clínicos associando a presença de anticorpos antifosfolípides com trombose vascular ${ }^{(1)}$.

A síndrome de anticorpo antifosfolípide ou síndrome antifosfolípide (SAF) é caracterizada por trombose arterial, venosa ou microvascular associadas com a persistência de

\begin{abstract}
Objective: To describe clinical and laboratorial features as well as outcome in a paediatric series with defined diagnosis of antiphospholipid syndrome. Methods: A descriptive-retrospective report from a pediatric tertiary referral, with case ascertainment by vascular events identification, either venous thrombosis or arterial occlusion, anti-cardiolipin antibodies (IgG and IgM) titres and lupus anticoagulant tests. Results: Five cases, being two boys and three girls, were identified in the last five years. Venous thrombosis occurred in brain sinus vessels (2), fibular (2), popliteal (1), femoral (1), intestinal (1) and renal (1) veins, followed by arterial occlusion in the gut (1), kidneys (1) halux (1) this resulted in digit gangrene as a recurrent event occurring during warfarin treatment. A spontaneous abortion occurred in an adolescent with thrombocytopenic purpura evolving into haemolytic anemia (Evans Syndrome) and bleeding fatal outcome. Laboratory investigation resulted in at least one positive titre of IgG and/or IgM anticardiolipin antibodies in all of the cases, being considered as primary antiphospholipid syndrome. Three cases have been followed under oral anticoagulation treatment. Conclusion: Cerebral and extremities venous thrombosis were the most frequent events in this series. This points to early diagnosis and team approach for investigation and treatment.
\end{abstract}

Keywords: anticardiolipin antibodies, antiphospholipid syndrome, Evans syndrome, thrombosis

anticorpos antifosfolípides circulantes. Os critérios diagnósticos mais utilizados, atualmente, foram propostos em 1999, sendo conhecidos como critérios de Sapporo ${ }^{(2)}$ e revisados recentemente em Sidney ${ }^{(3)}$. Define-se a SAF pela presença de um critério clínico - trombose vascular ou perda fetal - e um critério laboratorial definido como títulos médios ou altos de anticorpo anticardiolipina IgG e/ou IgM com título clinicamente significativo (> 40GPL ou MPL), teste do anticoagulante lúpico ou anticorpo anti-beta 2 glicoproteína I (anti-B2GPI) de classe IgG e/ou IgM.

Recebido em 8/1/2008. Aprovado, após revisão, em 10/10/2008. Declaramos a inexistência de conflitos de interesse

1. Mestranda da disciplina de Reumatologia Pediátrica do Departamento de Pediatria da Faculdade de Medicina de Botucatu da Universidade Estadual Paulista (Unesp) 2. Professora adjunta e livre-docente da disciplina de Reumatologia Pediátrica do Departamento de Pediatria da Faculdade de Medicina de Botucatu da Unesp. Endereço para correspondência: Claudia Saad Magalhães, Departamento de Pediatria da Faculdade de Medicina de Botucatu da Unesp, 18618-970, Botucatu, SP, e-mail: claudi@fmb.unesp.br 
A síndrome antifosfolípide (SAF) é chamada primária quando ocorre isoladamente, ou secundária se associada com outra doença auto-imune, ocorrendo freqüentemente em associação com o lúpus eritematoso sistêmico juvenil (LESJ). Contudo, os anticorpos antifosfolípides (APA) podem ocorrer transitoriamente após infecções virais, sem as repercussões vasculares.

A presença de APA em crianças tem sido investigada intensamente no LESJ, no qual o maior número de manifestações clínicas foi descrito ${ }^{(4,5)}$. Os APA foram detectados também em outras doenças auto-imunes, como a artrite idiopática juvenil ${ }^{(6)}$, em outras manifestações não auto-imunes, como a epilepsia ${ }^{(7)}$, e como fenômeno pósinfeccioso ${ }^{(8)}$.

A SAF primária é rara, assim como a SAF na faixa etária pediátrica. Em um estudo de coorte, o início da SAF ocorreu antes dos 15 anos em 2,8\% dos pacientes ${ }^{(9)}$. Ainda não há critérios válidos para o diagnóstico da SAF pediátrica, mas análise das séries de casos publicados até o presente indica as suas características singulares. Um registro internacional de SAF pediátrica ${ }^{(10)}$ foi recentemente proposto na Paediatric Rheumatology European Society (PRES), com base nos critérios de Sidney ${ }^{(3)}$.

O presente estudo teve como objetivo descrever as características clínicas, laboratoriais e de desfecho de uma série de casos com diagnóstico definido de SAF pediátrica primária.

\section{MÉTODOS}

Um estudo descritivo retrospectivo foi realizado por meio da identificação de um evento vascular, trombose venosa ou oclusão arterial, em pacientes pediátricos acompanhados em um centro de referência terciária, nos últimos cinco anos. Foram coletadas as seguintes informações clínicas e laboratoriais: sexo, idade, idade do diagnóstico, tempo de acompanhamento, manifestação clínica inicial atribuível à SAF, doença auto-imune subjacente, história familiar de doença auto-imune, manifestações clínicas durante o seguimento, aspectos laboratoriais do diagnóstico e características do desfecho. As manifestações clínicas foram confirmadas de acordo com os critérios estabelecidos, utilizando-se de métodos de imagem ou de estudo histopatológico. O diagnóstico de trombose venosa profunda foi por meio de ultra-som Doppler. Os eventos arteriais foram confirmados por apresentação clínica, estudo histopatológico ou arteriografia. As tromboses dos seios venosos foram confirmadas por ressonância nuclear magnética (RNM) e angiorressonância. A trombocitopenia foi definida como a contagem de plaquetas menor que $150.000 / \mathrm{mm}^{3}$. A determinação laboratorial de anticorpos anticardiolipina foi realizada utilizando ensaios imunoenzimáticos (ELISA) comercialmente disponíveis (Inova Quanta Life ACA IgG/IgM ELISA), sendo considerados positivos os títulos maiores de 21 unidades fosfolípides $\operatorname{IgG}$ e IgM, presentes em pelo menos duas ocasiões, com, pelo menos, três meses de intervalo entre as dosagens. $\mathrm{O}$ teste do anticoagulante lúpico foi realizado por meio da inibição de testes de coagulação dependentes de fosfolípides, ou seja, a inibição do tempo de tromboplastina parcial ativada e o tempo do veneno de víbora de Russel ${ }^{(3)}$.

Os critérios diagnósticos da SAF foram os do registro internacional da $\operatorname{PRES}^{(10)}$. Estes critérios preliminares são sumarizados no Quadro 1. O projeto teve aprovação do Comitê de Ética em Pesquisa da Faculdade de Medicina de Botucatu.

Quadro I

CRITÉRIOS PRELIMINARES ${ }^{\S}$ PARA A CLASSIFICAÇÃO DA SAF PEdiátrica segundo a Paediatric Rheumatology European SOCIETy (PRES) $)^{10}$

\begin{tabular}{ll}
\hline Critérios clínicos & Trombose vascular \\
& Um ou mais episódios trombóticos, arterial, venoso \\
& ou de pequenos vasos em qualquer órgão ou tecido, \\
confirmados por métodos objetivos e inequívocos & (imagem ou histopatologia) na ausência de inflamação \\
& de parede vascular. \\
Critérios laboratoriais & 1. Anticorpos anticardiolipina de classe IgG e/ou IgM \\
& no soro ou plasma \\
& Devem estar presentes em títulos médios ou altos \\
& ( 40 GPL ou MPL, ou percentil > 99) em duas ou mais \\
& ocasiões, com intervalo de, pelo menos, 12 semanas, \\
& por meio de ensaio ELISA padronizado. \\
& 2. Anticorpo anti- $\beta$ glicoproteína-I de classe IgG e/ou \\
& IgM no soro ou plasma \\
& Devem estar presentes em título > percentil 99, em \\
& duas ou mais ocasiões, com intervalo de, pelo menos, \\
& 12 semanas, por meio de ensaio ELISA padronizado. \\
& 3. Anticoagulante lúpico no plasma \\
& Deve estar presente em duas ou mais ocasiões, com \\
& intervalo de, pelo menos, 12 semanas, e detectado de \\
& acordo com a International Society on Thrombosis and \\
& Hemostasis Guidelines.
\end{tabular}

A SAF pediátrica será considerada se houver um critério clínico e pelo menos um critério laboratorial.

\section{RELATO DE CASOS}

\section{CASO 1}

Uma jovem de 14 anos havia sido acompanhada por hematologista com plaquetopenia e o diagnóstico de púrpura trombocitopênica auto-imune, tendo sido tratada com prednisona oral em doses altas por nove meses. O tratamen- 
to foi interrompido mediante a gravidez, evoluindo com abortamento espontâneo de um embrião viável de $43 \mathrm{~mm}$ no primeiro trimestre. Três semanas após teve o diagnóstico de pneumonia com derrame pleural, evoluindo com abdome agudo por gangrena intestinal maciça. Foi submetida à ressecção intestinal ampla, em duas cirurgias, preservandose apenas $10 \mathrm{~cm}$ de intestino delgado e a válvula ileocecal. Foram observados múltiplos trombos arteriais e venosos em todas as arcadas mesentéricas ao exame histopatológico. Foi encaminhada um mês após enterectomia, com o diagnóstico de síndrome do intestino curto. Apresentava vômitos, icterícia, dor torácica, dispnéia, hepatoesplenomegalia, escarros hemoptóicos e melena. A investigação do evento trombótico resultou: hemoglobina $10,2 \mathrm{~g} \%$, hematócrito $29,3 \%$, plaquetas $11.000 / \mathrm{mm}^{3}$, GB $18200 /$ $\mathrm{mm}^{3}$, com predomínio de segmentados e desvio à esquerda; reticulócitos 3,04\%; anticorpos anti-nucleares (ANA) com título de 1:80; VDRL positivo; testes de Coombs direto e indireto positivos; VHS $17 \mathrm{~mm} / \mathrm{h}$; proteína C reativa 8,5 $\mathrm{mg} \%$ (valor de referência $\leq$ a $1 \mathrm{mg} \%$ ); sedimento urinário com numerosas hemácias, bilirrubina direta $11,1 \mathrm{mg} \%$, bilirrubina indireta de 0,6 mg\%; TGO $38 \mathrm{UI} / \mathrm{mL}$; TGP 37 $\mathrm{UI} / \mathrm{mL}$; DHL $2.076 \mathrm{UI} / \mathrm{mL}$ (valor de referência: 313 a $618 \mathrm{UI} / \mathrm{mL}$ ); hemocultura positiva para C. albicans. Radiografias de tórax seriadas mostrando persistência de infiltrado do tipo intersticial. A determinação única de anticorpos antifosfolípides foi: anticardiolipina $\operatorname{IgM} 110 \mathrm{MPL}, \operatorname{IgG}$ 150 GPL e o teste do anticoagulante lúpico foi positivo. A paciente foi diagnosticada como síndrome antifosfolípide associada à anemia hemolítica auto-imune ou síndrome de Evans, tendo sido tratada com hidrocortisona, transfusões de concentrado de plaquetas e hemácias, nutrição parenteral total, oxigenioterapia, vitamina $\mathrm{K}$, antibioticoterapia de amplo espectro com a associação cefepime, vancomicina e anfotericina $\mathrm{B}$ e inibidores da bomba de prótons. Mediante queda de hemoglobina por intensificação da hemólise e trombocitopenia persistente recebeu três infusões $(2 \mathrm{~g} / \mathrm{kg})$ de imunoglobulina por via intravenosa alternadas com 4 infusões de rituximabe $375 \mathrm{mg} / \mathrm{m}^{2} /$ semana. Após seis semanas houve estabilização da anemia hemolítica. Após recuperação da trombocitopenia, foi iniciada a anticoagulação heparínica, com controles diários de anticoagulação mantidos dentro dos parâmetros esperados. Mantinha-se dispnéica em todo o período e teve hemorragia súbita e intensa de vias aéreas superiores e inferiores, evoluindo a óbito por choque hipovolêmico. Foi visualizado sangue à laringoscopia. Clinicamente o local mais provável de sangramento foi de origem pulmonar, embora a autópsia não tenha sido autorizada, o que limitou a identificação da localização precisa da hemorragia. A última dosagem de plaquetas resultou $413.000 / \mathrm{mm}^{3}$. A suspeita inicial de embolia pulmonar não foi confirmada.

\section{CASO 2}

Um menino de 10 anos desenvolveu insuficiência renal aguda aos 2 anos e 7 meses, sem qualquer fator desencadeante identificado. O ultra-som Doppler documentou a ausência de fluxo renal à direita. Um infarto renal isquêmico foi confirmado por cintilografia e arteriografia, sendo o paciente submetido à nefrectomia. A histologia renal demonstrou tromboses venosas e oclusão arterial no hilo renal. Foi, então, encaminhado por nefrologista mediante a identificação de anticorpos antifosfolípides. Durante o acompanhamento não havia recebido nenhum tratamento anticoagulante. As dosagens iniciais de anticorpo anticardiolipina foram qualitativas, com resultados positivos em duas dosagens, com intervalo maior de três meses entre elas. A primeira dosagem quantitativa evidenciou anticorpos anticardiolipina $\operatorname{IgM}$ de $23 \mathrm{MPL}, \mathrm{IgG}$ de 22 GPL e teste do anticoagulante lúpico negativo, ANA 1:80, anti-DNA negativo, anti-ENA RNP e Sm negativos. Durante seguimento teve convulsões com sinais de atividade epiléptica de localização parietoccipital direita ao eletroencefalograma, iniciando tratamento com carbamazepina e ácido acetilsalicílico (AAS) $100 \mathrm{mg} /$ dia. Atualmente apresenta função renal estável, mantendo-se em boas condições clínicas.

\section{CASO 3}

Um menino de 9 anos, portador de asma, teve início súbito de cefaléia frontoparietal, intensa e associada a tonturas, náuseas e episódio de perda da consciência. Manteve-se afebril durante todo o período e a análise do liquor e do fundo de olho foram normais. Após oito dias de cefaléia persistente e emese, foi submetido à RNM e angiorressonância que evidenciaram trombose venosa do seio sagital. Os exames laboratoriais da fase aguda foram: hemograma normal, VHS $13 \mathrm{~mm} / \mathrm{h}$, PCR negativa, urina I normal, cultura de líquido cefalorraquidiano negativa; dosagem de fator de von Willebrand normal; proteínas $\mathrm{C}$ e $S$ da coagulação normais, teste do látex semiquantitativo para o fator reumatóide positivo, ANA 1:80, anti-DNA, anti-ENA RNP e Sm negativos; C3 e C4 normais; dosagem de anticardiolipina IgM positiva (39 MPL), anticardiolipina IgG normal (14 GPL) e anticoagulante lúpico negativo. O paciente recebeu tratamento com anticoagulação heparínica 
e cumarínica, sendo encaminhado por neurologista para acompanhamento na reumatologia pediátrica.

A dosagem de anticardiolipina foi repetida cinco e 12 meses após o evento, mantendo-se os valores elevados e limítrofes, respectivamente. Dois anos após, teve convulsão e foi submetido novamente a RNM e eletroencefalograma, com resultados normais. Manteve-se em acompanhamento sem seqüelas ou anormalidades de neuroimagem, em uso de anticoagulação cumarínica mantendo INR (international normalized ratio) entre 2 e 3.

\section{CASO 4}

Uma menina de 9 anos foi encaminhada por cirurgião vascular por causa de trombose venosa profunda oclusiva extensa. O acometimento das veias femoral comum e superficial, poplítea e fibulares foi confirmado por duplex venoso. Recebeu tratamento com anticoagulação com heparina de baixo peso molecular e cumarínicos. A investigação laboratorial revelou hemograma e contagem de plaquetas normais, teste do látex semiquantitativo para o fator reumatóide positivo, C3 $62,7 \mathrm{mg} \%$ (valor de referência 88 a $201 \mathrm{mg} \%$ ), C4 5,4 mg\% (valor de referência 16 a 47 mg\%), imunoglobulinas normais, ANA 1: 320 de padrão homogêneo, auto-anticorpos positivos (anti-DNA, antiRo, anti RNP e Sm), função renal normal (urina I, uréia e creatinina), VDRL negativo e duas dosagens de anticorpo anticardiolipina IgM e IgG positivas, com títulos sempre maiores ou iguais a 40 , com mais de 12 semanas de intervalo entre as dosagens. A dosagem de anticoagulante lúpico não foi possível por causa de uso de anticoagulantes orais para manter INR em níveis entre 3 e 4.

Evoluiu com gangrena com amputação parcial do hálux na vigência de anticoagulação cumarínica. O mapeamento duplex da aorta abdominal mostrou estenose maior que $70 \%$ em terço médio proximal da artéria femoral superficial e afilamento da artéria tibial anterior no terço distal. A paciente está em acompanhamento ambulatorial há um ano e meio, em boas condições clínicas, em uso de anticoagulação oral, hidroxicloroquina, nifedipina, AAS (100 $\mathrm{mg} /$ dia) e fotoproteção.

\section{CASO 5}

Uma jovem de 15 anos teve cefaléia occipital persistente com emese por 12 dias sem melhora com analgésicos. Foi submetida a tomografia computadorizada de crânio, que revelou a trombose de seios venosos. Recebeu dexametasona com melhora da cefaléia e dos vômitos. Negava quaisquer sintomas sistêmicos. A RNM de encéfalo evidenciou realce após contraste endovenoso em seios transverso e sigmóide esquerdo. A angiorressonância confirmou falha no enchimento vascular. Recebeu anticoagulação com heparina de baixo peso molecular seguida por cumarínicos, alcançando níveis satisfatórios de anticoagulação.

Foi encaminhada por neurologista e os exames laboratoriais foram: hemograma normal, proteína $\mathrm{C}$ reativa $\mathrm{e}$ VHS normais, urina I normal, ANA 1: 640, látex positivo, dosagem de proteínas C e $S$ normais. Anti-DNA e antiENA negativos. A dosagem de anticardiolipina realizada por ocasião do evento foi $\operatorname{IgM}$ limítrofe (13 MPL) e IgG (13 GPL) negativa. Oito semanas após IgM (17 MPL) e IgG (17 GPL) limítrofes. Oito meses após dosagem inicial apresentava IgM (13 MPL) e IgG positivo (24 GPL). A dosagem do anticoagulante lúpico foi negativa. A paciente evoluiu sem seqüelas neurológicas, permanecendo em uso contínuo de cumarínicos, com níveis de INR entre 2 e 3. A RNM de encéfalo realizada oito meses após o evento agudo foi normal.

As principais manifestações clínicas, laboratoriais e de desfecho são sumarizadas na Tabela 1 .

\section{DISCUSSÃO}

Foi apresentada uma série de casos pediátricos de SAF avaliados retrospectivamente em um único centro. Todos os casos tiveram o diagnóstico inicial de trombose venosa ou oclusão arterial aguda. A prevalência de anticorpos antifosfolípides em associação a tromboembolismo venoso em crianças varia de $0 \%$ a $23,8 \%{ }^{(11)}$. Há outras condições, como câncer, cardiopatia congênita e trauma, também associadas ao maior risco de trombose na faixa etária pediátrica ${ }^{(12)}$. Um estudo canadense demonstrou em 137 crianças hospitalizadas que a incidência de trombose venosa foi de 5,3/10.000 admissões hospitalares ou de $0,07 / 10.000$ crianças $^{(12)}$. Porém, esse estudo não incluiu, especificamente, os casos de trombose secundários à SAF, e nem os casos de oclusão arterial. Neste estudo, os pacientes apresentavam ainda, como fatores associados, o uso de cateteres intravenosos. Entre as particularidades da SAF em crianças e adolescentes, quando comparada aos adultos, a morbidade gestacional é referida como infreqüente, assim como os outros fatores pró-trombóticos, como a aterosclerose, o tabagismo, o uso de anticoncepcionais orais, que contribuem em menor proporção para a trombose ${ }^{(13)}$.

Outros fatores, além da presença de anticorpos antifosfolípídes, podem estar associados com a trombose na faixa 
TABELA I

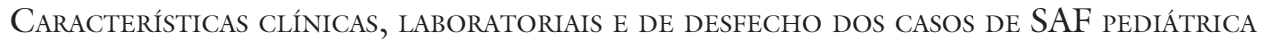

\begin{tabular}{|c|c|c|c|c|c|c|c|c|}
\hline Caso & Sexo & Idade & $\begin{array}{l}\text { Sede da } \\
\text { trombose }\end{array}$ & $\begin{array}{l}\text { Manifestações } \\
\text { clínicas }\end{array}$ & $\begin{array}{c}\text { Anticorpos } \\
\text { antifosfolipedes }\end{array}$ & $\begin{array}{c}\text { Alterações } \\
\text { laboratoriais }\end{array}$ & $\begin{array}{c}\text { Tempo de } \\
\text { acompanhamento }\end{array}$ & Desfecho \\
\hline 1 & $\mathrm{~F}$ & $\begin{array}{c}14 \text { anos e } \\
6 \text { meses }\end{array}$ & $\begin{array}{l}\text { Artéria e veia } \\
\text { mesentérica }\end{array}$ & $\begin{array}{l}\text { Aborto espontâneo, } \\
\text { púrpura trombocitopênica, } \\
\text { anemia hemolítica } \\
\text { Gangrena intestinal }\end{array}$ & $\begin{array}{c}\text { aCL IgG } 150 \mathrm{GPL} \\
\text { aCL IgM } 110 \mathrm{MPL} \\
\text { anticoagulante lúpico } \\
\text { positivo }\end{array}$ & $\begin{array}{c}\text { Coombs direto e } \\
\text { indireto positivos } \\
\text { ANA } 1: 80\end{array}$ & 1 mês & $\begin{array}{l}\text { Enterectomia, síndrome } \\
\text { do intestino curto, } \\
\text { coagulopatia, candidíase } \\
\text { sistêmica, óbito }\end{array}$ \\
\hline 2 & M & $\begin{array}{l}2 \text { anos e } \\
7 \text { meses }\end{array}$ & $\begin{array}{l}\text { Artéria e veia } \\
\text { renal }\end{array}$ & $\begin{array}{c}\text { Insuficiência } \\
\text { renal } \\
\text { aguda, } \\
\text { hipertensão arterial }\end{array}$ & $\begin{array}{c}\text { aCL IgG } 22 \text { e } 18 \mathrm{GPL} \\
\text { aCL IgM } 23 \text { e } 23 \mathrm{MPL} \\
\text { anticoagulante lúpico } \\
\text { negativo }\end{array}$ & ANA $1: 80$ & 12 anos & $\begin{array}{l}\text { Recuperação clínica } \\
\text { após nefrectomia, } \\
\text { função renal estável, } \\
\text { síndrome epiléptica }\end{array}$ \\
\hline 3 & M & $\begin{array}{l}9 \text { anos e } \\
7 \text { meses }\end{array}$ & $\begin{array}{l}\text { Seio venoso } \\
\text { (SNC) }\end{array}$ & Cefaléia & $\begin{array}{c}\text { aCL IgG } 14 \text { e } 7 \mathrm{GPL} \\
\text { aCL IgM } 39 \text { e } 29 \mathrm{MPL} \\
\text { anticoagulante lúpico } \\
\text { negativo }\end{array}$ & $\begin{array}{l}\text { ANA 1:80, dosagem } \\
\text { de fator de von } \\
\text { Willebrand, proteínas } \\
\text { C e S normais }\end{array}$ & 3,8 anos & $\begin{array}{c}\text { Recuperação sem } \\
\text { seqüelas, em uso de } \\
\text { anticoagulação oral. Um } \\
\text { episódio convulsivo }\end{array}$ \\
\hline 4 & $\mathrm{~F}$ & 9 anos & $\begin{array}{l}\text { Veias femoral } \\
\text { comum e } \\
\text { superficial, } \\
\text { poplítea e } \\
\text { fibulares } \\
\text { Artéria digital } \\
\text { do hálux }\end{array}$ & $\begin{array}{l}\text { Trombose venosa } \\
\text { profunda } \\
\text { Gangrena do hálux }\end{array}$ & $\begin{array}{c}\text { aCL IgG } 60 \text { e } 50 \mathrm{GPL} \\
\text { aCL IgM } 50 \text { e } 40 \mathrm{MPL} \\
\text { anticoagulante lúpico } \\
\text { não realizado }\end{array}$ & $\begin{array}{c}\text { ANA 1:320, } \\
\text { anti-DNA +, } \\
\text { anti-RNP +, } \\
\text { anti-Sm +, } \\
\text { anti-Ro +, } \\
\text { FR (látex) +, } \\
\text { diminuição de } \\
\text { C3 e C4 }\end{array}$ & 4,2 anos & $\begin{array}{l}\text { Recuperação com } \\
\text { seqüela por amputação } \\
\text { da falange distal do } \\
\text { hálux, em uso de } \\
\text { anticoagulação oral }\end{array}$ \\
\hline 5 & $\mathrm{~F}$ & 15 anos & $\begin{array}{l}\text { Seio venoso } \\
\text { (SNC) }\end{array}$ & Cefaléia & $\begin{array}{c}\text { aCL IgG } 17 \text { e } 24 \text { GPL } \\
\text { aCL IgM } 17 \text { e } 13 \text { MPL } \\
\text { anticoagulante lúpico } \\
\text { negativo }\end{array}$ & $\begin{array}{l}\text { ANA } 1: 640, \text { teste do } \\
\text { látex positivo, } \\
\text { dosagem de proteínas } \\
\text { Ce } S \text { normais }\end{array}$ & 1,8 anos & $\begin{array}{l}\text { Recuperação sem } \\
\text { seqüelas, em uso de } \\
\text { anticoagulação oral }\end{array}$ \\
\hline
\end{tabular}

aCL IgG = anticardiolipina IgG (normal: menor ou igual a 15; limítrofe 16 a 20; positivo: 21 a 80; positivo alto: maior de $81 \mathrm{GPL}$ ) aCL IgM = anticardiolipina IgM (normal: menor ou igual a 12,5; limítrofe: 13 a 20; positivo: 21 a 80; positivo alto: maior de 81 MPL)

$\S$ Não foi realizada dosagem de anticoagulante lúpico por causa da anticoagulação oral.

etária pediátrica. As trombofilias hereditárias, causadas por defeitos genéticos no sistema de coagulação, levam ao maior risco de tromboses venosas.

Recomenda-se, atualmente, a pesquisa sistemática de trombofilias hereditárias e auto-imunes em todos os casos de trombose na faixa etária pediátrica ${ }^{(11)}$. Na série em estudo, a pesquisa de trombofilias hereditárias foi realizada em apenas dois dos casos, mediante a disponibilidade deste exame no período da observação clínica. Porém, todos os casos tiveram o diagnóstico de trombofilia auto-imune, de acordo com os critérios propostos para a SAF pediátrica, embora os valores de anticardiolipina tenham sido menores que aqueles propostos para os adultos ${ }^{(3)}$ (Tabela 1 ). Apenas dois dos pacientes descritos apresentaram dosagem de anticardiolipina $\operatorname{IgG}$ ou $\operatorname{IgM}$ maiores que 40 unidades fosfolípides, o que confirma a necessidade de critério diagnóstico específico para a faixa etária pediátrica.

A associação com outras doenças auto-imunes também deve ser sempre pesquisada mediante o diagnóstico de SAF. Alguns autores levantam a hipótese de que a SAF primária e a SAF secundária ao lúpus sejam espectros de uma mesma doença. Gattorno et al. ${ }^{(14)}$ estudaram 14 casos pediátricos com SAF acompanhados por períodos de 2 a 16 anos (mediana 6 anos). Desses, dez pacientes ainda mantinham critério para SAF primária, dois desenvolveram lúpus, um manifestava aspectos similares ao lúpus e um desenvolveu linfoma de Hodgkin.

A série em estudo confirma os achados de Gattorno et $a l^{(14)}$ quanto ao espectro de auto-imunidade, tendo dois dos casos citados anteriormente o diagnóstico de lúpus provável ou doença lúpus símile, o que reforça a necessidade de acompanhamento em longo prazo. Os dados preliminares do registro internacional de $\mathrm{SAF}^{(10)}$, incluindo 107 crianças e adolescentes de 13 países, confirmam o maior acometimento com trombose venosa profunda em extremidades e trombose cerebral, além da maior associação com manifestações hematológicas e cutâneas em pacientes com doenças auto-imunes, quando comparadas com os casos de SAF primária.

Entre os casos anteriormente citados, todos apresentavam anticorpos antinucleares positivos (ANA) e dois apresentavam diversos auto-anticorpos (anti-DNA, ENA-Sm, ENA-RNP e fator reumatóide), contudo, sem os critérios diagnósticos completos para LESJ. Por definição, todos os pacientes descritos seriam classificados como portadores de SAF primária e um caso teve associação com trombocitope- 
nia e anemia hemolítica auto-imune (síndrome de Evans). Nesse caso, a paciente apresentava anemia hemolítica com aumento de reticulócitos, DHL e bilirrubina direta, apesar de bilirrubina indireta normal, possivelmente por causa da colestase secundária à infecção sistêmica (candidíase).

A síndrome de Evans consiste do acometimento simultâneo ou seqüencial de anemia hemolítica e trombocitopenia auto-imune, tendo sido descrita em associação com imunodeficiências primárias, doença do tecido conectivo e doenças linfoproliferativas, incluindo a síndrome linfoproliferativa auto-imune (ALPS), recentemente descrita em associação com a $S \mathrm{~F}^{(15)}$. Na série citada, uma adolescente apresentou aspectos marcantes desta associação pelo desfecho fatal, possivelmente associado à coagulopatia, a despeito do tratamento imunossupressor e imunobiológico ${ }^{(16)}$. Anticorpos antiprotrombina também não foram determinados neste caso.

Ressalta-se, ainda, que dois pacientes apresentaram crises epilépticas durante sua evolução, e não está claro se tal manifestação pode estar relacionada com a SAF. Em 1996, von Scheven et al. ${ }^{(17)}$ descreveram uma série em que, de cinco pacientes com SAF primária, três apresentaram manifestações neurológicas em sua evolução: um caso de síndrome epiléptica do tipo crise de ausência, um caso de síndrome epiléptica focal e um caso de coréia, todos com melhora dos sintomas após tratamento com corticosteróides e/ou AAS.

Três dos pacientes do presente estudo manifestaram-se com associação de tromboses arterial e venosa. Um dos casos apresentou recorrência, desenvolvendo oclusão arterial

\section{REFERÊNCIAS}

1. Ravelli A, Martini A. Antiphospholipid syndrome. Pediatr Clin North Am. 2005;52:469-91.

2. Wilson WA, Gharavi AE, Koike T, Lockshin MD, Branch DW, Piette JC, et al. International consensus statement on preliminary classification criteria for definite antiphospholipid syndrome: report of an international workshop. Arthritis Rheum. 1999;42:1309-11.

3. Miyakis S, Lockshin MD, Atsumi T, Branch DW, Brey RL, Cervera $\mathrm{R}$, et al. International consensus statement on an update of the classification criteria for definite antiphospholipid syndrome (APS). J Thromb Haemost. 2006;4:295-306.

4. Berube C, Lesley M, Silverman E, David M, Saint Cyr C, Laxer R, et al. The relationship of antiphospholipid antibodies to thromboembolic events in pediatric patients with systemic lupus erythematosus: a cross-sectional study. Pediatr Res. 1998;44:351-5.

5. Campos LM, Kiss MH, D’Amico EA, Silva CA. Antiphospholipid antibodies and anti-phospholipid syndrome in 57 children aguda e gangrena do hálux em vigência de anticoagulação cumarínica, indicada pela trombose venosa profunda. Recorrências são descritas em $28,6 \%$ dos pacientes, principalmente naqueles que não fizeram uso de anticoagulação após a primeira manifestação trombótica ${ }^{(18)}$.

Ainda não há consenso sobre o tratamento de pacientes pediátricos com SAF. O conhecimento sobre anticoagulação em crianças ainda é insuficiente, e há discussões sobre a intensidade e a duração da anticoagulação. A recomendação atual para os pacientes com trombose secundária à presença de anticorpos antifosfolípídes é a anticoagulação com heparina seguida por anticoagulação oral com cumarínicos. Em casos de trombose venosa, o INR deverá ser mantido entre 2 e 3 , e em casos de trombose arterial ou recidiva da trombose ou oclusão arterial em vigência de cumarínicos, entre 3 e $4^{(19)}$.

Entre as limitações da presente investigação está a indisponibilidade de anticorpos antibeta- 2 glicoproteína I para a investigação laboratorial de rotina, dos anticorpos antiprotrombina e da pesquisa sistemática de trombofilias hereditárias, além do tempo decorrido entre o evento trombótico e a investigação laboratorial em um dos casos (caso 2). Esse caso ficou insuspeito por ocasião da nefrectomia, o que alerta para a abordagem multidisciplinar destes casos.

Concluindo, mediante a gravidade e as implicações em longo prazo do diagnóstico e tratamento da SAF, a análise desta série alerta para a necessidade de diagnóstico e intervenção precoces, abordagem multidisciplinar e investigação laboratorial oportuna.

and adolescents with systemic lupus erythematosus. Lupus. 2003;12:820-6.

6. Avcin I, Ambrozic A, Bozic B, Acetto M, Kveder T, Rozman B. Estimation of anticardiolipin antibodies and lupus anticoagulant in a prospective longitudinal study of children with juvenile idiopathic arthritis. Clin Exp Rheumatol. 2002;20:101-8.

7. Cimaz R, Romeo A, Scarano A, Avcin T, Viri M, Veggiotti P et al. Prevalence of anticardiolipin, anti-Beta2-glycoprotein I and anti-prothrombin antibodies in young patients with epilepsy. Epilepsia. 2002;43:52-9.

8. Male C, Klaus L, Eichmer S, Kyrle PA, Kapiotis S, Wank H, et al. Clinical significance of lupus anticoagulant in children. J Pediatr. 1999;134:199-205.

9. Cervera R, Piette JC, Font J, Khamashta MA, Shoenfeld Y, Campos MT, et al, and the Euro-Phospholipid Project Group. Antiphospholipid syndrome: clinical and immunologic manifestations and patterns of disease expression in a cohort of 1,000 patients. Arthritis Rheum. 2002;46:1019-27. 
10. Avcin T, Cimaz R, Silverman ED, Cervera R, Gattorno M, Garay $S$, et al. Register for pediatric patients with antiphospholipid syndrome: clinical and immunologic features of 107 children. Arthritis Rheum. 2007; Suppl 56:S830 (Abstract 2197).

11. Revel-Vilk S, Kenet G. Thrombophilia in children with venous thromboembolic disease. Thromb Res. 2006;118: 59-65,.

12. Andrew M, David M, Adams M, Ali K, Anderson R, Barnard $\mathrm{D}$, et al. Venous thromboembolic complications (VTE) in children: first analyses of the Canadian registry of VTE. Blood. 1994;83:1251-7,

13. Nuss R, Hays T, Manco-Jonhson M. Childhood thrombosis. Pediatrics. 1995;96:291-4,

14. Gattorno M, Falcini F, Ravelli A, Zulian F, Buoncompagni A, Martini G, et al. Outcome of primary antiphospholipid syndrome in childhood. Lupus. 2003;12:449-53.
15. Avcin T, Jazbec J, Kuhar M, Zupancic M, Rozman B. Evan's syndrome associated with antiphospholipid antibodies. J Pediatr Haematol Oncol. 2003;25:755-6,.

16. Zecca M, Nobili B, Ramenghi U, Perotta S, Amendola G, Roseto $\mathrm{P}$, et al. Rituximab for the treatment of refractory auto-immune haemolytic anaemia in children. Blood. 2003;101:3857-61.

17. von Scheven E, Athreya BH, Rose CD, Goldsmith DP, Morton L. Clinical characteristics of antiphospholipid antibody syndrome in children. J Pediatr. 1996;129:339-45.

18. Berkun Y, Padeh S, Barash J, Uziel Y, Harel L, Mukamel M, et al. Antiphospholipid syndrome and recurrent thrombosis in children. Arthritis Care Res. 2006;55: 850-5.

19. Kamat AV, D’Cruz DP, Hunt BJ. Managing antiphospholipid antibodies and antiphospholipid syndrome in children. Haematologica. 2006;91:1674-80. 